IEEE ISIE International Symposium on Industrial Electronics, Rio de Janeiro Brazil, pp.190-195, June 2015.

http://ieeexplore.ieee.org/stamp/stamp.jsp?tp=\&arnumber $=7281467$

ISBN: 978-1-4673-7553-5

DOI: $10.1109 /$ ISIE.2015.7281467

This material is posted here with permission of the IEEE. Such permission of the IEEE does not in any way imply IEEE endorsement of any of Group of Energy and Power Electronics, University of Minho, products or services. Internal or personal use of this material is permitted. However, permission to reprint/republish this material for advertising or promotional purposes or for creating new collective works for resale or redistribution must be obtained from the IEEE by writing to pubs-permissions@ieee.org. By choosing to view this document, you agree to all provisions of the copyright laws protecting it.

(C) 2015 IEEE 


\title{
A Novel Concept of Unidirectional Bridgeless Combined Boost-Buck Converter for EV Battery Chargers
}

\author{
Vítor Monteiro $^{1}$, J. G. Pinto ${ }^{1}$, Bruno Exposto ${ }^{1}$, Luís F. C. Monteiro ${ }^{2}$, Carlos Couto ${ }^{1}$, João L. Afonso ${ }^{1}$ \\ ${ }^{1}$ ALGORITMI Research Centre - University of Minho, Guimarães - Portugal \\ ${ }^{2}$ Universidade do Estado do Rio de Janeiro, Campus Francisco Negrão de Lima - 20559-900, Rio de Janeiro, Brasil \\ ${ }^{1}$ \{vitor.monteiro | gabriel.pinto | bruno.exposto | carlos.couto | joao.l.afonso\}@algoritmi.uminho.pt ${ }^{2}$ Imonteiro@uerj.br
}

\begin{abstract}
This paper presents a novel concept of unidirectional bridgeless combined boost-buck converter for electric vehicles (EVs) battery chargers. The proposed converter is composed by two power stages: an ac-dc front-end converter used to interface the power grid and the dc-link, and a dc-dc back-end converter used to interface the dc-link and the batteries. The ac-dc converter is a bridgeless boost-type converter and the dc-de converter is an interleaved buck-type converter. The proposed converter operates with sinusoidal grid current and unitary power factor for all operating power levels. Along the paper is described in detail the proposed converter for EV battery chargers: the circuit topology, the different stages describing the principle of operation, the power control theory, and the current control strategy, for both converters. Along the paper are presented several simulation results for a maximum power of $3.5 \mathrm{~kW}$.
\end{abstract}

Keywords-EV Battery Charger; Bridgeless; Battery Charger; Electric Vehicle.

\section{INTRODUCTION}

The electric vehicle (EV) is seen as a fundamental element for contributing to reduce the greenhouse gases emissions, for the migration to a new paradigm in the transport sector, and for a more sustainable and efficient mobility [1][2]. However, the power grids were not designed to support unregulated battery charging process, where the power quality [3][4] and the power grid stability [5][6] are important issues. In order to perform the EV battery charging process from the power grid is required an on-board EV battery charger, which is used to convert ac voltages and currents into dc and control the charging process. Typically, the power level of these chargers is between $3 \mathrm{~kW}$ [7][8] and $7 \mathrm{~kW}$ [9], and are composed by two power stages: an ac-dc front-end converter to interface the power grid and other dc-dc back-end converter to interface the batteries [10][11]. The ac-dc converter should operate with sinusoidal grid current and high power factor, and the dc-dc converter with controlled voltage and current in the dc side.

In [12] is presented a review about the actual status of EV battery chargers, where are included the topologies of converters, the charging power levels and the infrastructures for EV. In the literature can be found several studies about ac-dc front-end converters with power-factor-correction (PFC) capabilities, for instance, in [13] is presented a comparison about the basic converter topologies for PFC based in the basic dc-dc converters. In particular, a comprehensive review focused in PFC topologies based in the boost converter is presented in [14]. Besides the full-bridge and half-bridge PFC converters (boost-type), the main topologies are based in the bridgeless converters [15][16], and multilevel converters [17][18]. Similar studies can be found in [19] and [20]. In the literature can also be found several studies about dc-dc back-end converters, where the main topologies are based in the half-bridge converter [21], the interleaved converters [22], and cascade converters [23]. In this context, this paper presents a novel concept of unidirectional bridgeless combined boost-buck converter for EV battery chargers. This converter, presented in Fig. 1, is composed by two converters: an ac-dc front-end that is used to interface the power grid and the dc-link; and a dc-dc back-end that is used to interface the dc-link and the batteries. The ac-dc converter is a bridgeless boost-type converter with voltage-doubler characteristic, i.e., the dc-link is split in two. The dc-dc converter is a buck-type converter with interleaved characteristic. The main advantages of the proposed converter are: the bridgeless characteristic when compared with the traditional PFC boost converter [24]; the dc-link voltage-doubler characteristic which is useful for universal-line PFC front-end converters [25]; and the interleaved characteristic of the dc-dc converter [26]. The interleaved characteristics is important for allowing increase the frequency of the ripple in the batteries current and the size and volume of the output filters when compared with the traditional solutions [26]. In section II is presented the principle of operation of the proposed converter, i.e., are described in

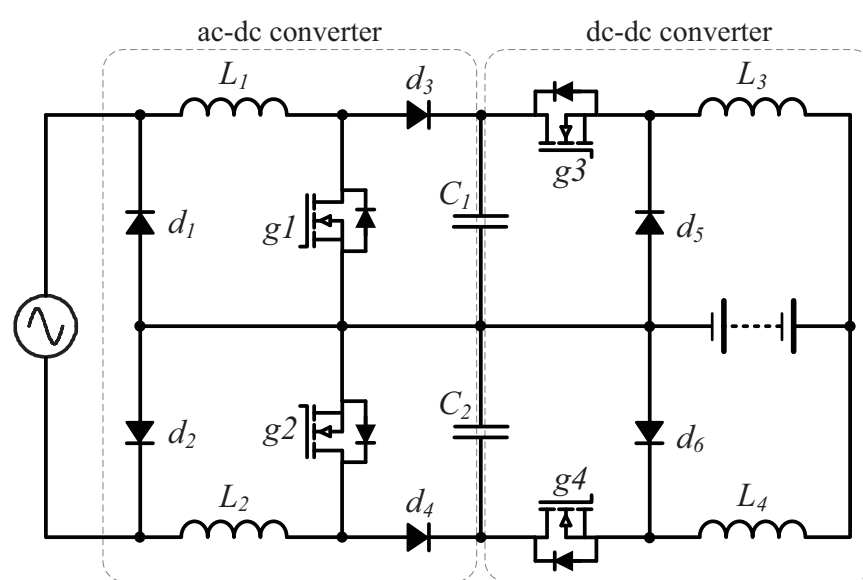

Fig. 1. Proposed unidirectional bridgeless combined boost-buck converter for EV battery chargers. 


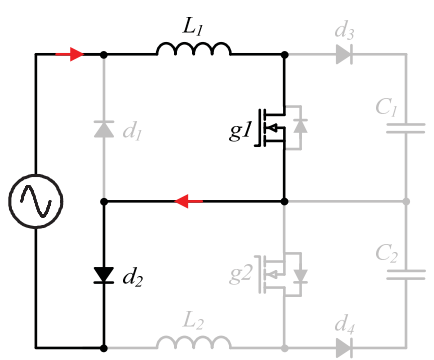

(a)

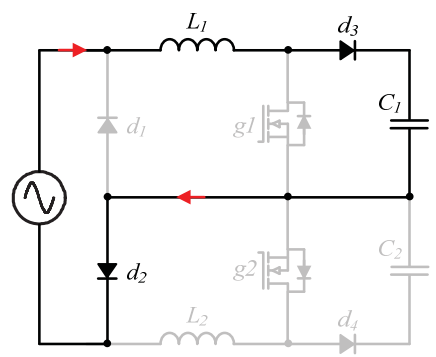

(b)

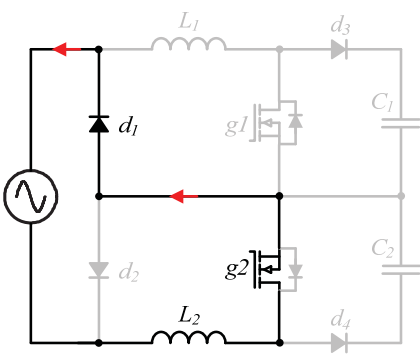

(c)

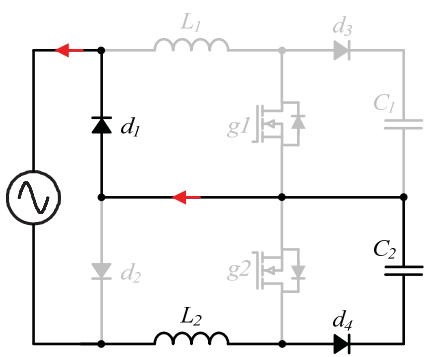

(d)

Fig. 2. Operation stages of the ac-dc converter: (a) $L_{1}$ stores energy from the power grid; (b) $L_{1}$ delivers energy to the dc-link; (c) $L_{2}$ stores energy from the power grid; (d) $L_{2}$ delivers energy to the dc-link.

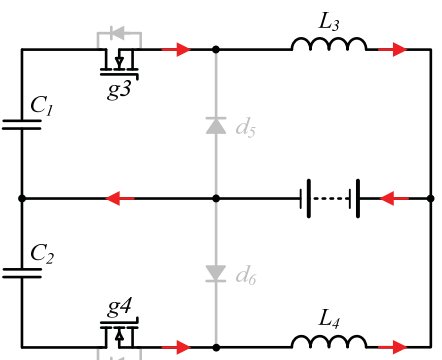

(a)

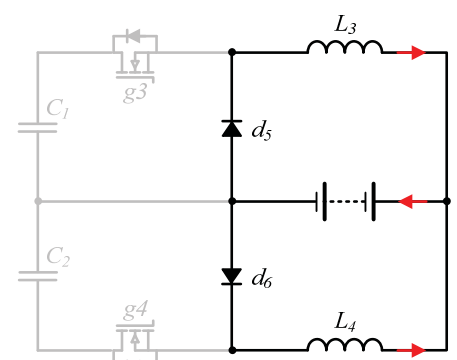

(b)

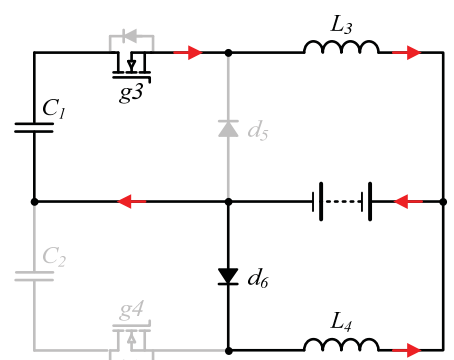

(c)

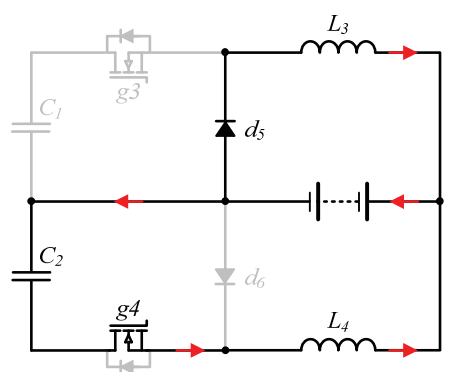

(d)

Fig. 3. Operation stages of the dc-dc converter: (a) $V_{D C 1}$ and $V_{D C 2}$ deliver energy and $L_{2}$ and $L_{3}$ store energy; (b) $L_{2}$ and $L_{3}$ deliver energy to the batteries; (c) $V_{D C 1}$ delivers energy, $L_{3}$ stores energy and $L_{4}$ delivers energy; (d) $V_{D C 2}$ delivers energy, $L_{4}$ stores energy and $L_{3}$ delivers energy.

detail the different power stages of the ac-dc front-end converter and the dc-dc back-end converter. In section III is described the controller design, i.e., the main steps that allow obtain the grid current reference for the ac-dc front-end converter and the voltage or current reference for the dc-dc back-end converter in order to charge the batteries. In this section are also presented the control strategies that allow synthetize the current or voltage references. The simulation results of the proposed converter rated for $3.5 \mathrm{~kW}$ are presented in section IV. Finally, section V presents the main conclusions.

\section{PRINCIPLE OF OPERATION}

As aforementioned, the proposed converter (cf. Fig. 1) is a combined converter, i.e., it is composed by two power stages: an ac-dc front-end bridgeless boost-type converter and a dc-dc back-end interleaved buck-type converter. Fig. 2 shows the operation stages of the ac-dc converter. The ac-dc front-end converter has four main operation stages. During the positive semi cycle, when the MOSFET $g l$ is on the inductor $L_{l}$ stores energy, i.e., the current follows from the power grid through the MOSFET $g 1$ and the diode $d 2$ (cf. Fig. 2(a)). When the MOSFET $g l$ is off the inductor $L_{l}$ deliver energy to the dc-link, i.e. the current follows through the diodes $d 2$ and $d 3$ (cf. Fig. 2(b)). During the negative semi cycle, when the MOSFET $g 2$ is on the inductor $L_{2}$ stores energy, i.e., the current follows from the power grid through the MOSFET $g 2$ and the diode $d 1$ (cf. Fig. 2(c)). When the MOSFET $g 2$ is off the inductor $L_{2}$ deliver energy to the dc-link, i.e. the current follows through the diodes $d 1$ and $d 4$ (cf. Fig. 2(d)). Fig. 3 shows the operation stages of the dc-dc converter. The dc-dc back-end converter has also four main operation stages. When the MOSFETs $g 3$ and $g 4$ are on the inductors $L_{3}$ and $L_{4}$ stores energy, i.e., the current follows from the dc-link to the battery through the MOSFETs $g 3$ and $g 4$ (cf. Fig. 3(e)). When the MOSFETs $g 3$ and $g 4$ are off the inductors $L_{3}$ and $L_{4}$ deliver energy, i.e., the current follows to the battery through the diodes $d 5$ and $d 6$ (cf. Fig. 3(f)). When the MOSFET $g 3$ is on and the MOSFET $g 4$ is off the inductor $L_{3}$ stores energy and the inductor $L_{4}$ delivers energy, i.e., the current follows to the battery through the MOSFET $g 3$ and the diode $d 6$ (cf. Fig. 3(g)). When the MOSFET $g 3$ is off and the MOSFET $g 4$ is on the inductor $L_{3}$ delivers energy and the inductor $L_{4}$ stores energy, i.e., the current follows to the battery through the MOSFET $g 4$ and the diode $d 5$ (cf. Fig. 3(h)).

\section{A. Front-end Converter}

The ac-dc front-end converter is used to transfer energy from the power grid to the dc-link. As shown in Fig. 1, this converter is mainly composed by two MOSFETs ( $g 1$ and $g 2$ ), by two inductive filters $\left(L_{1}\right.$ and $\left.L_{2}\right)$, by two diodes ( $d 1$ and $d 4$ ) and by a split dc-link. The power grid phase is connected to the inductor $L_{1}$ and the neutral is connected to the inductor $L_{2}$. The middle point of the dc-link is connect to the middle point of the input diodes $d 1$ and $d 2$, therefore, the voltage in the dc-link is always greater than the double of the maximum instantaneous value of the power grid voltage. With this converter, during the positive semi cycle is used the MOSFET $g l$ and the diodes $d 3$ and $d 4$. During the negative semi cycle is used the MOSFET $g 2$ and the diodes $d 4$ and $d 1$. Fig. 4 shows in detail the current in the inductor $L_{l}$ (cf. Fig. 4(a)), i.e., the grid current $\left(i_{g}\right)$, and the gate pulses of the MOSFET $g 1$ (cf. Fig. 4(b)).

\section{B. Back-end Converter}

The dc-dc back-end converter is used to transfer energy from the dc-link to the batteries. As shown in Fig. 1, the dc-dc converter is mainly composed by two MOSFETs ( $g 3$ and $g 4$ ), by two inductive filters $\left(L_{3}\right.$ and $\left.L_{4}\right)$ and by two diodes ( $d 5$ and d6). As it can be seen, the inductor L3 and L4 are connected to the battery through the same point, and the middle point of the dc-link is connect to the middle point of the output diodes $d 5$ 


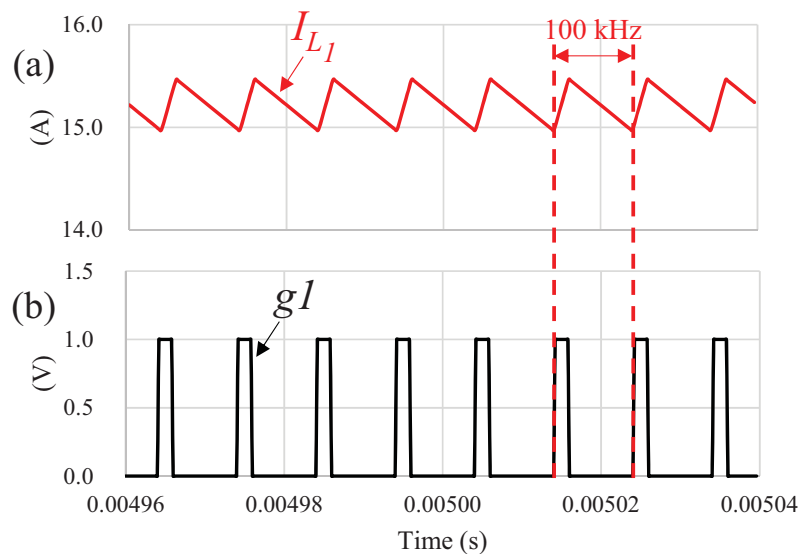

Fig. 4. Operation of the ac-dc converter: (a) Current in the inductor $L_{l}$ (i.e., the grid current); (b) Gate pulses of the MOSFET $g 1$.

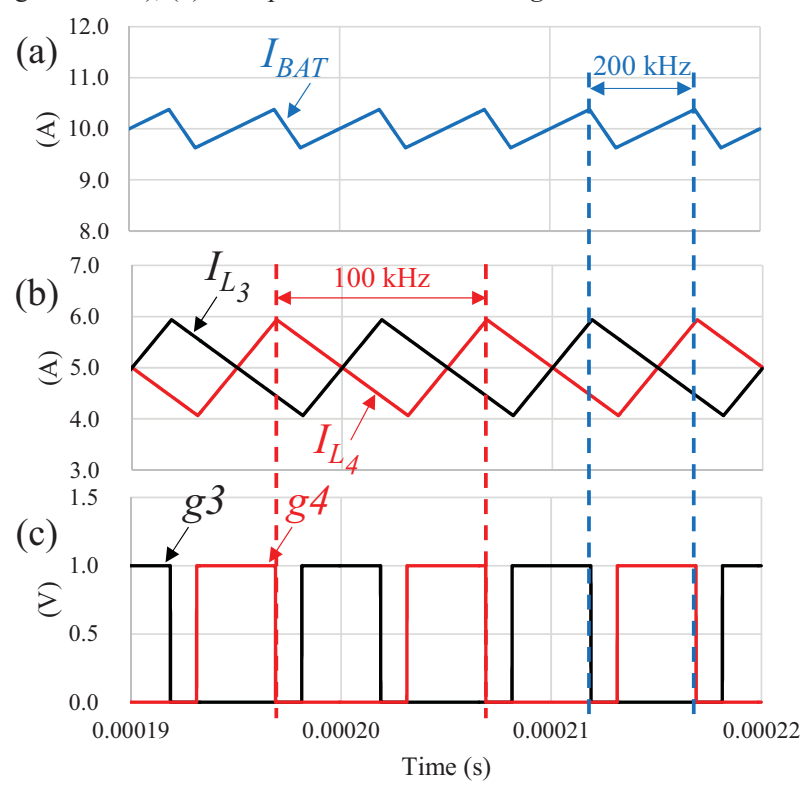

Fig. 5. Operation of the dc-dc converter: (a) Current in the batteries $\left(I_{B A T}\right)$; (b) Current in the inductors $L_{1}$ and $L_{2}$; (c) Gate pulses of the MOSFETs $g 3$ and $\mathrm{g} 4$.

and d6. This converter allows operates in interleaved mode, i.e., the current in the batteries is combined by the current from the inductors $L_{3}$ and $L_{4}$. Therefore, the ripple of current in the batteries is half of the ripple of current in each inductor and the resultant frequency is the double of the switching frequency. Fig. 5 shows in detail the current in the batteries, the current in the inductors $L_{3}$ and $L_{4}$ (cf. Fig. 5(a)), and the gate pulses of the MOSFETs $g 3$ and $g 4$ (cf. Fig. 5(b)).

\section{CONTROLLER Design}

This section presents the main steps of the digital controller design for the proposed converter, i.e., the power theory and the current control strategy for the ac-dc and dc-dc converters.

\section{A. Power Theory}

The power theory of the controller allows obtain the grid current references for the ac-dc front-end converter. In order to simplify the power theory description, it is assumed that the power grid voltage is composed only by the fundamental component. In the digital controller is used a phase-locked loop (pll) algorithm, allowing to obtain sinusoidal references to the grid current [27]. Assuming a power grid voltage $\left(v_{g}\right)$ and a grid current $\left(i_{g}\right)$ only with fundamental component, the active power $\left(P_{g}\right)$ in the ac side is defined by:

$$
P_{g}=V_{g} I_{g} \cos (\varphi),
$$

where, $V_{g}$ and $I_{g}$ are rms values and $\varphi$ corresponds to the angle phase between the voltage and the current. Taking into account that the proposed converter operates with sinusoidal current and high power factor, the angle phase is zero, i.e., $\cos (\varphi)=1$. Therefore, it can be defined a conductance $(G)$ according to:

$$
G=\frac{P_{g}}{V_{g}^{2}} .
$$

From the instantaneous values of the power grid voltage and grid current, can be defined:

$$
i_{g}(t)=G v_{g}(t) .
$$

Using the conductance defined in (2) and the equation (3), the instantaneous grid current reference can be defined by:

$$
i_{g}{ }^{*}(t)=\frac{P_{g}}{V_{g}^{2}} v_{g}(t),
$$

where, $v_{g}(t)$ is substituted by the $p l l$ in the digital controller. For the proposed converter, neglecting the losses, the active power $P_{g}$ can be separately in two terms corresponding, respectively, to the power to maintain constant the dc-link voltage $\left(V_{D C}\right)$ and the power to charge the batteries (through the dc-dc back-end converter). Therefore, (4) can be rearranged to:

$$
i_{g}^{*}(t)=\frac{P_{D C}(t)+V_{B A T}(t) I_{B A T}(t)}{V_{g}^{2}} v_{g}(t),
$$

where, $P_{D C}$ is obtained from a PI controller. It is important to highlight that the voltage in the capacitor $C_{1}$ is controlled during the positive semi cycle and the voltage in the capacitor $C_{2}$ during the negative semi cycle.

\section{B. Current Control Strategy}

In order to simply the description of the current control strategy, Fig. 6 shows the equivalent circuit of the proposed converter for EV battery chargers.

\section{1) Front-end Converter}

From Fig. 6, analyzing the voltages and currents between the power grid and the converter, it can be established for the power grid voltage $\left(v_{g}\right)$ that:

$$
v_{g}(t)=v_{l}(t)+v_{\text {conv }}(t) .
$$

Substituting the voltage in the inductor by the time derivative of its current multiplied by its inductance and rearranging in order to the voltage $\left(v_{c}\right)$ that the converter must produce is obtained:

$$
v_{c}(t)=v_{g}(t)-L \frac{d i_{g}(t)}{d t} .
$$

Taking into account that is used a digital control strategy, the derivative of the power grid current $\left(i_{g}\right)$ in $(7)$ can be 


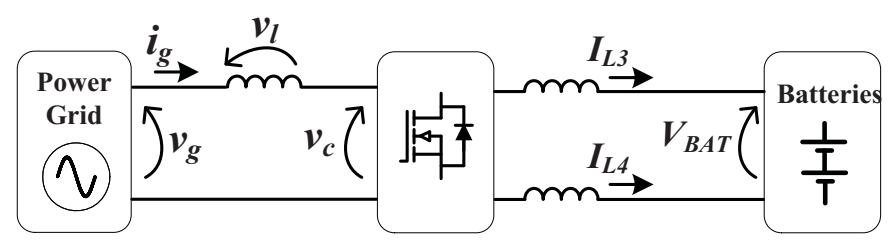

Fig. 6. Representation of the voltages and currents in the proposed converter.

substituted by its discrete implementation using the forward Euler method according to:

$$
\frac{d i_{g}}{d t}=\frac{i_{g}[k+1]-i_{g}[k]}{T_{S}} .
$$

Using (7) and the discrete implementation of (8) results in:

$$
v_{c}[k]=v_{g}[\mathrm{k}]-L f_{s}\left(i_{g}[k+1]-i_{g}[k]\right),
$$

where, $f_{s}$ is the sampling frequency, and $k, k+1$, are respectively, the actual and next samples. The current in the instant $k+1\left(i_{g}[k+1]\right)$ should be equal to the current reference in the instant $k\left(i_{g} *[k]\right)$. Therefore, (9) can be rewritten for:

$$
v_{c}[k]=v_{g}[\mathrm{k}]-L f_{s}\left(i_{g}{ }^{*}[k]-i_{g}[k]\right) .
$$

The voltage $v_{c}[k]$ is the reference that is compared with a $100 \mathrm{kHz}$ center-aligned triangular carrier in order to control the state of the MOSFETs.

\section{2) Back-end Converter}

From Fig. 6, analyzing the voltages and currents between the converter and the batteries, it can be established:

$$
\begin{aligned}
& V_{D C 1}(t)=V_{B A T}(t)+V_{L_{3}}(t) . \\
& V_{D C 2}(t)=V_{B A T}(t)+V_{L_{4}}(t) .
\end{aligned}
$$

where, $V_{B A T}$ is the voltage in the batteries and $V_{L 3}$ and $V_{L 4}$ are, respectively, the voltages across the inductors. The discrete implementation of (11) results in:

$$
\begin{aligned}
& V_{D C 1}[k]=V_{B A T}[k]+L_{3} f_{S}\left(I_{L_{3}}[k+1]-I_{L_{3}}[k]\right) \\
& V_{D C 2}[k]=V_{B A T}[k]+L_{4} f_{S}\left(I_{L_{4}}[k+1]-I_{L_{4}}[k]\right)
\end{aligned}
$$

where, $I_{L}[k+1]$ must be equal to the reference in the instant $[k]$. In order to the dc-dc converter operates with interleaved characteristics are used two triangular carriers lagged 180 degrees, i.e., to obtain the gate pulses to the MOSFETs $g 3$ and g4.

\section{Simulation Results}

In this section are presented the main simulation results of the proposed converter, which were obtained with PSIM 9.0 software. TABLE I presents the specifications and key components of the proposed converter that were used in the simulation mode.

Fig. 7(a) shows some simulation results of the power grid voltage $\left(v_{g}\right)$ and the grid current $\left(i_{g}\right)$ during $50 \mathrm{~ms}$. As it can be seen, the grid current is sinusoidal and in phase with the power grid voltage. These results were obtained with a power grid
TABLE I

SPECIFICATION AND KEY PARAMETERS OF THE PROPOSED CONVERTER

\begin{tabular}{ccc}
\hline \hline Parameters & Value & Unit \\
\hline Grid Voltage & $230 \pm 10 \%$ & $\mathrm{~V}$ \\
Grid Frequency & $50 \pm 1 \%$ & $\mathrm{~Hz}$ \\
Maximum Input Power & 3.5 & $\mathrm{~kW}$ \\
Output dc Voltage Range & 100 to 400 & $\mathrm{~V}$ \\
Maximum Output Current & 10 & $\mathrm{~A}$ \\
Total Power Factor @ Full Load & 0.99 & - \\
Switching Frequency & 100 & $\mathrm{kHz}$ \\
\hline Inductors $L_{1}, L_{2}$ & 1.2 & $\mathrm{mH}$ \\
Inductors $L_{3}, L_{4}$ & 500 & $\mu \mathrm{H}$ \\
Dc-link Capacitors $C_{1}, C_{2}$ & 5 & $\mathrm{mF}$ \\
Batteries Nominal Voltage & 266 & $\mathrm{~V}$ \\
Maximum Batteries Charging Voltage & 302 & $\mathrm{~V}$ \\
Maximum Batteries Charging Current & 10 & $\mathrm{~A}$ \\
\hline \hline
\end{tabular}
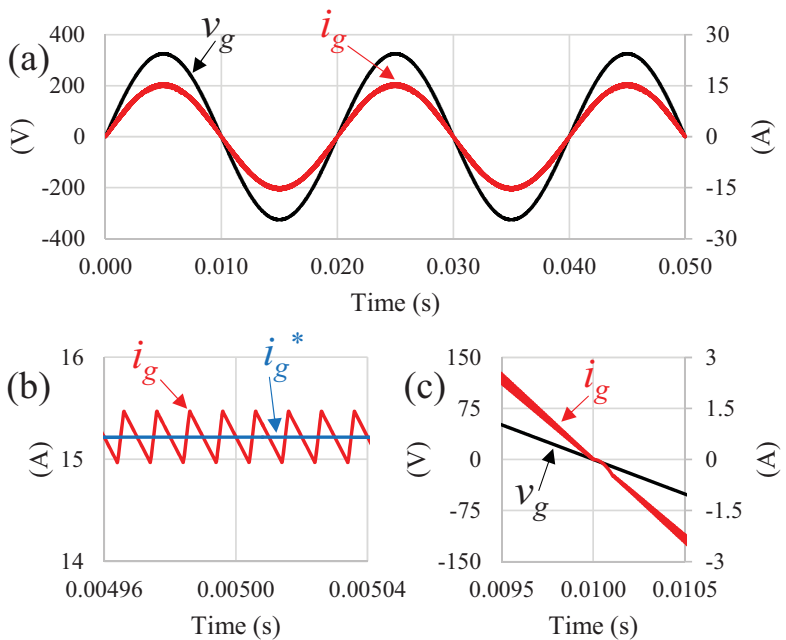

Fig. 7. Operation of the ac-dc converter: (a) Power grid voltage $\left(v_{g}\right)$ and grid current $\left(i_{g}\right)$ during $50 \mathrm{~ms}$; (b) Detail of the grid current $\left(i_{g}\right)$ and its reference $\left(i_{g}{ }^{*}\right)$; (c) Detail when the power grid voltage $\left(v_{g}\right)$ and the grid current $\left(i_{g}\right)$ crosses zero.

voltage of $230 \mathrm{~V}(\mathrm{rms})$ and a power of $3.5 \mathrm{~kW}$. Fig. 7(b) shows in detail the grid current $\left(i_{g}\right)$ and its reference $\left(i_{g}{ }^{*}\right)$ in order to confirm the operation of the current control strategy. Fig. 7(c) shows in detail when the power grid voltage $\left(v_{g}\right)$ and the grid current $\left(i_{g}\right)$ crosses zero. In order to show that the grid current varies linearly with the power grid voltage, Fig. 8(a) shows the power grid voltage $\left(v_{g}\right)$ in function of the grid current $\left(i_{g}\right)$. Fig. 8(b) shows in detail variation near of zero, i.e., when the power grid voltage is between $10 \mathrm{~V}$ and $-10 \mathrm{~V}$ and the grid current is between $0.5 \mathrm{~A}$ and $-0.5 \mathrm{~A}$, where it is possible observe that the variation is slightly distorted. As described in the principle of operation (cf. Section II) is used the inductor $L_{l}$ during the positive semi cycle and the inductor $L_{2}$ during the negative semi cycle. Fig. 9(a) shows the current in the inductor $L_{l}$ and the voltage in the MOSFET $s l$ and Fig. 9(b) shows the current in the inductor $L_{2}$ and the voltage in the MOSFET $s 2$. The maximum voltage in each MOSFET is half of the dc-link voltage. Taking into account that the charging power varies during the battery charging process, the grid current also varies and consequently the value of the total harmonic distortion (THD\%). Fig. 10 shows the grid current THD\% in function of 


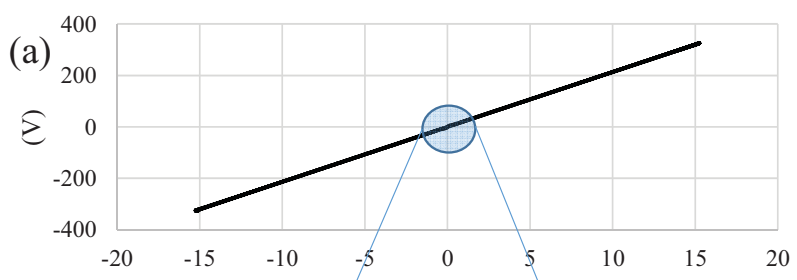

(A)

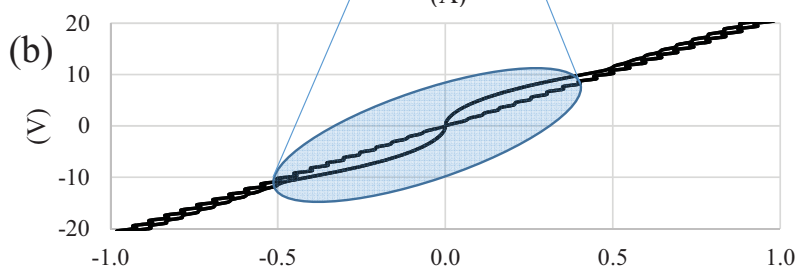

(A)

Fig. 8. Power grid voltage $\left(v_{g}\right)$ in function of the grid current $\left(i_{g}\right)$ : (a) For a power of $3.5 \mathrm{~kW}$; (b) Detail of the variation near of zero.
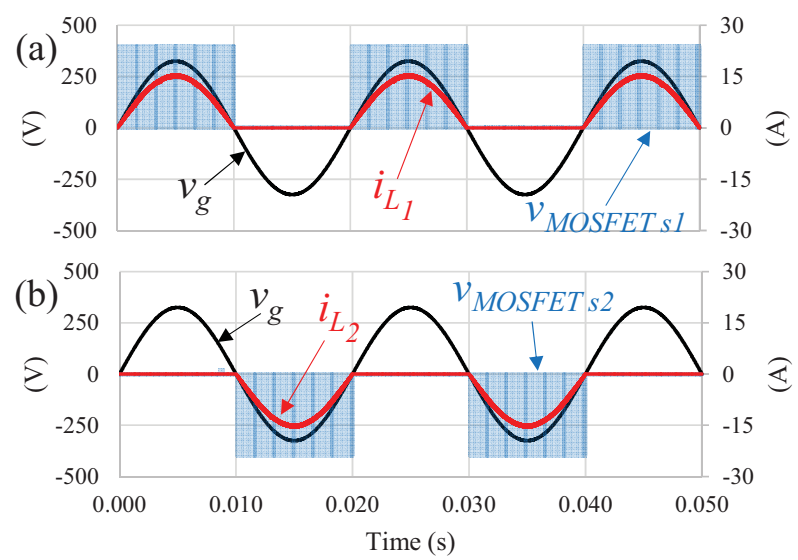

Fig. 9. Operation of the ac-dc converter: (a) Current in the inductor $L_{1}$ and voltage in the MOSFET $s 1$; (b) Current in the inductor $L_{l}$ and voltage in the MOSFET $s 1$.

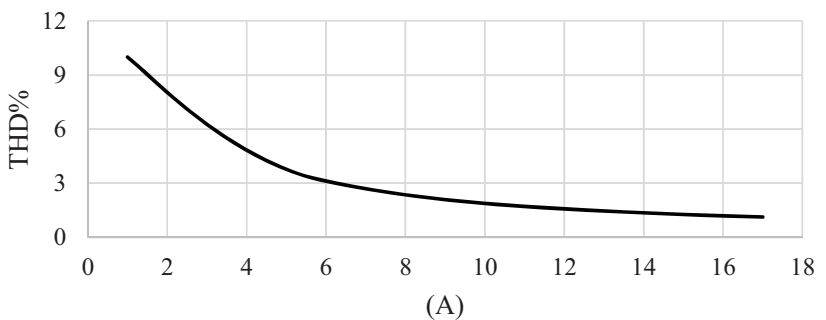

Fig. 10. Grid current THD $\%$ in function of the grid current (rms).

the grid current (rms). Fig. 11 shows in detail the dc-link voltage in each capacitor $\left(C_{1}\right.$ and $\left.C_{2}\right)$. Taking into account that the ac-dc converter is single-phase converter the dc-link voltage is not constant, i.e., it has a ripple about of $12 \mathrm{~V}$ with a frequency of $50 \mathrm{~Hz}$. Therefore, in order to avoid introduce the dc-link voltage oscillation into the control is used the mean value of the dc-link voltage, which is obtained according with:

$$
\overline{V_{D C}[k]}=\frac{1}{T} \sum_{n=1}^{T} V_{D C}[n] .
$$

Fig. 12 shows the battery charging current $\left(I_{B A T}\right)$ and voltage $\left(V_{B A T}\right)$ during a complete Li-Ion battery charging process, i.e., a battery charging process that consist in two charging stages: constant current followed by constant voltage.

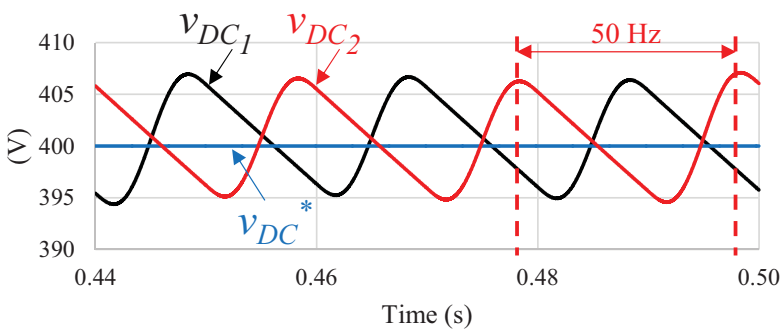

Fig. 11. Ripple of the dc-link voltage in each capacitor $\left(C_{1}\right.$ and $\left.C_{2}\right)$ and voltage reference $\left(v_{D C}{ }^{*}\right)$.

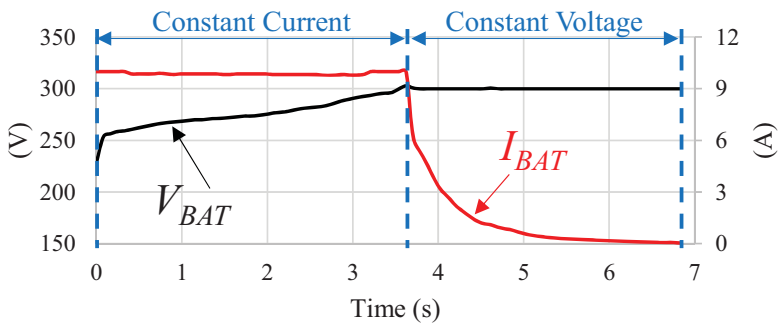

Fig. 12. Battery charging current $\left(I_{B A T}\right)$ and voltage $\left(V_{B A T}\right)$ during a complete Li-Ion battery charging process (constant current followed by constant voltage).

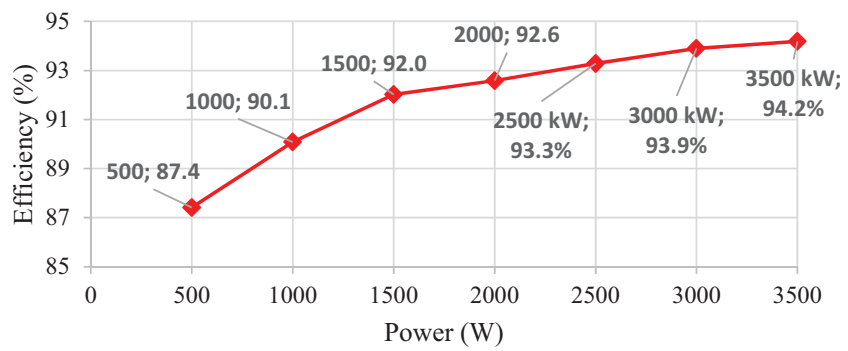

Fig. 13. Estimated efficiency of the proposed EV battery charger for a power range from $500 \mathrm{~W}$ to $3.5 \mathrm{~kW}$.

During the first stage (constant current) the batteries were charged with a constant current of 10 A during about 3.5 hours. This stage finish when the voltage reaches the specified value for the battery model $(302 \mathrm{~V})$. During the second stage (constant voltage) the batteries were charged with a constant voltage of $302 \mathrm{~V}$ during about 2.5 hours. This stage finish when the current consumed by the batteries falls to a residual value (near of zero). It is important to refer that this charging algorithm can be adjusted for other nominal values as well as for other technologies of batteries.

Fig. 13 shows the estimated efficiency of the proposed EV battery charger for a power range from $500 \mathrm{~W}$ to $3.5 \mathrm{~kW}$. In this estimated efficiency were considered the losses in the semiconductors (estimating conduction and switching losses), and in the input and output passive filters. This simulation result was obtained using the thermal module of the software PSIM. The thermal module considers the dynamic behavior of real semiconductors towards estimating switching and conduction losses.

\section{CONCLUSiOn}

This paper presents a novel concept of unidirectional bridgeless combined boost-buck converter specifically dedicated for electric vehicles (EVs) battery chargers. The proposed converter is composed by two power stages: a 
bridgeless boost-type ac-dc converter and an interleaved buck-type dc-dc converter. The proposed converter operates with sinusoidal grid current and unitary power factor. The simulation results show a total harmonic distortion of about $1.2 \%$ for a power of $3.5 \mathrm{~kW}$, and of $10 \%$ for a power of nearly $200 \mathrm{~W}$. Along the paper is presented in detail the proposed converter for EV battery chargers, including the different stages describing the principle of operation, the power control theory, and the current control strategy for both converters. The simulation results show in detail that the grid current is sinusoidal, and that it is in phase with the power grid voltage. In the paper are also presented simulation results during a complete EV Li-Ion battery charging process, which consists in two charging stages: constant current followed by constant voltage.

\section{ACKNOWLEDGMENT}

This work has been supported by FCT - Fundação para a Ciência e Tecnologia in the scope of the project: PEstUID/CEC/00319/2013. Mr. Vítor Monteiro was supported by the doctoral scholarship SFRH/BD/80155/2011 granted by the FCT agency.

\section{REFERENCES}

[1] Kaushik Rajashekara, "Present Status and Future Trends in Electric Vehicle Propulsion Technologies," IEEE J. Emerg. Sel. Topics Power Electron., vol.1, no.1, pp.3-10, Mar. 2013.

[2] Seshadri Srinivasa Raghavan, Alireza Khaligh, "Electrification Potential Factor: Energy-Based Value Proposition Analysis of Plug-In Hybrid Electric Vehicles," IEEE Trans. Veh. Technol., vol.61, no.3, pp.1052-1059, Mar. 2012.

[3] Thomas H. Bradley, Andrew A. Frank, "Design, demonstrations and sustainability impact assessments for plug-in hybrid electric vehicles," ELSEVIER Renewable and Sustainable Energy Reviews, pp.1-14, May 2007.

[4] Paul S. Moses, Sara Deilami, Amir S. Masoum, Mohammad A. S. Masoum, "Power Quality of Smart Grids with Plug-in Electric Vehicles Considering Battery Charging Profile," IEEE Innovative Smart Grid Technologies Conference Europe, pp.1-7, Oct. 2010.

[5] Farzad Rajaei Salmasi, "Control Strategies for Hybrid Electric Vehicles: Evolution, Classification, Comparison, and Future Trends," IEEE Trans. Veh. Technol., vol.56, no.5, pp.2393-2404, Sept. 2007.

[6] João A. Peças Lopes, Filipe Soares, Pedro M. Rocha Almeida, "Integration of Electric Vehicles in the Electric Power Systems," Proc. IEEE, vol.99, no.1, pp.168-183, Jan. 2011.

[7] Deepak S. Gautam, Fariborz Musavi, Murray Edington, Wilson Eberle, William G. Dunford, "An Automotive Onboard 3.3-kW Battery Charger for PHEV Application," IEEE Trans. Veh. Technol., vol.61, no.8, pp.3466-3474, Oct. 2012.

[8] J. G. Pinto, Vítor Monteiro, Henrique Gonçalves, João L. Afonso, "Onboard Reconfigurable Battery Charger for Electric VehiclesWith Traction-to-Auxiliary Mode," IEEE Trans. Veh. Technol., vol.63, no.3, pp.1104-1116, Mar. 2014.

[9] Jun-Young Lee, Hyung-Jun Chae, "6.6-kW Onboard Charger Design Using DCM PFC ConverterWith HarmonicModulation Technique and Two-Stage DC/DC Converter," IEEE Trans. Ind. Electron., vol.61, no.3, pp.1243-1252, Mar. 2014.

[10] T. Soeiro, T. Friedli, J. W. Kolar, "Three-Phase High Power Factor Mains Interface Concepts for Electric Vehicle Battery Charging Systems," IEEE APEC Applied Power Electronics Conference and Exposition, pp.2603-2610, Feb. 2012.
[11] Sanzhong Bai, Srdjan M. Lukic, "Unified Active Filter and Energy Storage System for an MWElectric Vehicle Charging Station," IEEE Trans. Power Electron., vol.28, no.12, pp.5793-5803, Dec. 2013.

[12] Murat Yilmaz, Philip T. Krein, "Review of Battery Charger Topologies, Charging Power Levels, and Infrastructure for Plug-In Electric and Hybrid Vehicles," IEEE Trans. Power Electron., vol.28, no.5, pp.2151-2169, May 2013.

[13] Huai Wei, Issa Batarseh, "Comparison of Basic Converter Topologies for Power Factor Correction," IEEE Proceedings of Southeastcon, pp.348-353, Apr. 1998.

[14] João Paulo M. Figueiredo, Fernando L. Tofoli, Bruno Leonardo A. Silva, "A Review of Single-Phase PFC Topologies Based on The Boost Converter," IEEE INDUSCON International Conference on Industry Applications, pp.1-6, Nov. 2010.

[15] Woo-Young Choi, Jung-Min Kwon, Bong-Hwan Kwon, “An Improved Bridgeless PFC Boost-Doubler Rectifier With High-Efficiency,” IEEE PESC Power Electronics Specialists Conference, Rohdes, pp.13091313, June 2008

[16] J. Biela, J.W. Kolar, G. Deboy, “Optimal Design of a Compact 99.3\% Efficient Single-Phase PFC Rectifier," IEEE APEC Applied Power Electronics Conference and Exposition, Palm Springs, CA, pp.13971404, Feb. 2010.

[17] José Rodríguez, Jih-Sheng Lai, Fang Zheng Peng, "Multilevel Inverters: A Survey of Topologies, Controls, and Applications," IEEE Trans. Ind. Electron., vol.49, no.4, pp.724-738, Aug. 2002.

[18] Jih-Sheng Lai, Fang Zheng Peng, "Multilevel Converters-A New Breed of Power Converters," IEEE Trans. Ind. Appl., vol.32, no.3, pp.509517, May 1996.

[19] Bhim Singh, Brij N. Singh, Ambrish Chandra, Kamal Al-Haddad, Ashish Pandey, Dwarka P. Kothari, "A Review of Single-Phase Improved Power Quality AC-DC Converters," IEEE Trans. Ind. Electron., vol.50, no.5, pp.962-981, Oct. 2003.

[20] Oscar García, José A. Cobos, Roberto Prieto, Pedro Alou, Javier Uceda, "Single Phase Power Factor Correction: A Survey," IEEE Transactions on Power Electronics, vol.18, no.3, pp.749-755, May 2003.

[21] Mamadou Baïlo Camara, Hamid Gualous, Frederic Gustin, Alain Berthon, Brayima Dakyo, "DC/DC Converter Design for Supercapacitor and Battery Power Management in Hybrid Vehicle Applications-Polynomial Control Strategy," IEEE Trans. Ind. Electron., vol.57, no.2, pp.587-597, Feb. 2010.

[22] Oscar García, Pablo Zumel, Angel de Castro, José A. Cobos, "Automotive DC-DC Bidirectional Converter Made With Many Interleaved Buck Stages," IEEE Trans. Power Electron., vol.21, no.3, pp.578-586, May 2006.

[23] Yu Du, Xiaohu Zhou, Sanzhong Bai, Srdjan Lukic, Alex Huang, "Review of Non-isolated Bi-directional DC-DC Converters for Plug-in Hybrid Electric Vehicle Charge Station Application at Municipal Parking Decks," IEEE APEC Applied Power Electronics Conference and Exposition, Palm Springs, CA, pp.1145-1151, Feb. 2010.

[24] Chan-Song Lee, Jin-Beom Jeong, Baek-Haeng Lee, Jin Hur, "Study on $1.5 \mathrm{~kW}$ Battery Chargers for Neighborhood Electric Vehicles," IEEE VPPC Vehicle Power and Propulsion Conference, pp.1-4, Sept. 2011.

[25] Yungtaek Jang, Milan M. Jovanovic, "Interleaved boost converter with intrinsic voltage-doubler characteristic for universal-line PFC front end," IEEE Trans. Power Electron., vol.22, no.4, pp.1394-1401, Jul. 2007. .

[26] Vítor Monteiro, J. G. Pinto, Bruno Exposto, João C. Ferreira, Carlos Couto, João L. Afonso, "Assessment of a Battery Charger for Electric Vehicles with Reactive Power Control," IEEE IECON Industrial Electronics Society, Montréal-Canada, pp.5124-5129, Oct. 2012.

[27] Masoud Karimi-Ghartemani, "Linear and Pseudolinear Enhanced Phased-Locked Loop (EPLL) Structures,” IEEE Trans. Ind. Electron., vol.61, no.3, pp.1464-1474, Mar. 2014. 